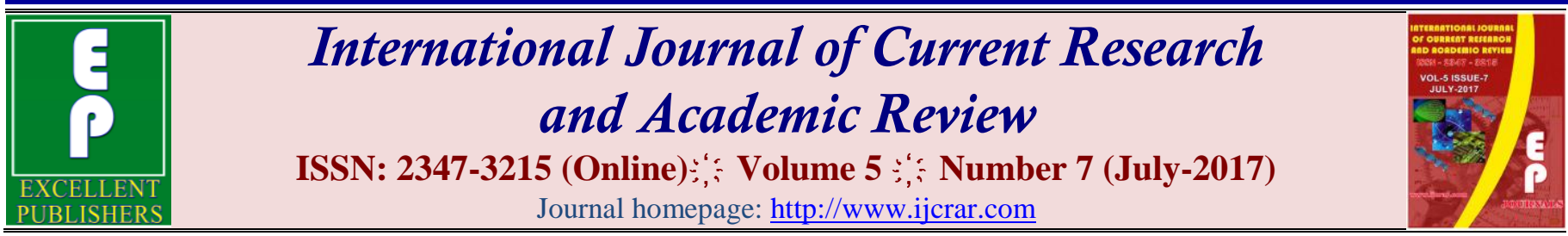

doi: https://doi.org/10.20546/ijcrar.2017.507.006

\title{
Preliminary Results from a Pilot Study on Effectiveness of Life Skills Training Package (LSTP) on Life Skills, Self Esteem, Quality of Life and Academic Performance among Children Residing in Selected Orphanages, Tamil Nadu, India
}

\author{
Joseph Jeganathan $^{1^{*}}$ and K. Reddemma ${ }^{2}$ \\ ${ }^{I}$ Department of Mental Health Nursing, Aladi Aruna College of Nursing, Alangulam, Tirunelvelli district, Tamil \\ Nadu, India \\ ${ }^{2}$ Nodal office, National consortium for PhD Nursing, St. Johns College of Nursing, Bangalore-34, Karnataka, India \\ *Corresponding author
}

\section{Abstract}

Millions of children live in the streets of cities scattered all over the world. In 2004, out of the total juveniles, the share of homeless children who were involved in various crimes was just 7.5 percent. Life skills refer to the competencies that an individual needs for sustaining and enriching life. WHO (1993) accordingly life skills are defined as "abilities for adaptive and positive behavior that enables individuals to deal effectively with the demands and challenges of everyday life". Various psychosocial factors and skill deficits leads to low selfesteem, poor communication skills and problem solving skills, poor decision making skills and lack of assertiveness were found to be linked with delinquency, school dropouts, smoking, drug abuse, teenage pregnancy, suicidal thoughts and health problems Learning of life skills essentially help to promote mental wellbeing. This study was conducted to evaluate the effectiveness of Life Skills Training package (LSTP) on Life Skills, Self Esteem, Quality of Life and Academic Performance of children residing in selected orphanages This study adopted a Quasi-experimental Pretest-posttest control group design. The present study was conducted at Sri Kanyakumari Gurukulam Girls Home, Alamelupuram, Karunkulam, Tamil Nadu and Rehoboth Happy girls Home, Nagercoil, Tamil Nadu. Children with age twelve years to eighteen years old comprise the sample for the present study, totally 20 girls were selected randomly, 10 from each orphanages were assigned to experimental group, and control group. Data was collected using Socio-demographic data sheet, Life Skills Scale, Vranda MN, (2007); Rosenberg Self-Esteem Scale, Rosenberg, M. (1965); WHOQOLBREF-26 and Academic record of the children. In the experimental group the Mean and SD of the pretest score in LSS 384.4 \pm 35.3 indicates that children have low life skills whereas after the LSTP the post test score $441.2 \pm 52.1$ revealed higher life skills and in the control group the pretest score in LSS $314.9 \pm 35.1$ and post test score was $315.6 \pm 30.1$ indicates lower life skills. Higher scores in the experimental group showed mastery over the life skills among children in orphanages In the experimental group the Mean and SD of the pretest score in SES 16.9 \pm 3.4 where as in the post test score it was $20.1 \pm 3.4$ revealed higher scores, Higher self-esteem and in the control group the pretest score was $13.9 \pm 2.9$ and the post test score was $14.8 \pm 2.7$. In the experimental group the Mean and SD of the pretest score in QOL was $94.7 \pm 12.9$ after the LSTP intervention higher score $100.6 \pm 13.9$ denotes that higher quality of life and in the control group the pretest score was $77.7 \pm 7.3$ and the post test score was $74.8 \pm 6.2$ Between group comparison revealed that the total score of life skills, there is significant difference $(\mathrm{p}<0.001)$ at all the levels of assessments (pre, post-I, II, III, IV) of the children between experimental and control group. With respect to self-esteem except pre test scores $(\mathrm{p}<0.05)$, and post assessments were found to be significant $(\mathrm{p}<0.001)$. The total score of quality of life have significant difference $(\mathrm{p}<0.001)$ at all the levels of assessments (pre, post-I, II, III, IV) between experimental and control group. In this present study the finding revealed a significant improvement in the Life skills, Self-esteem, Quality of life for the children in experimental group who attended the Life Skills Training Package.
\end{abstract}

\section{Article Info}

Accepted: 02 July 2017

Available Online: 20 July 2017

\section{Keywords}

Children in orphanages, Life Skills Training Package. 


\section{Introduction}

Life skills refer to the competencies that an individual needs for sustaining and enriching life ${ }^{1}$. WHO (1993) accordingly life skills are defined as "abilities for adaptive and positive behavior that enables individuals to deal effectively with the demands and challenges of everyday life". There are innumerable life skills are specific to certain situations while others are of generic in nature. Based on various theoretical perspectives, as well as intervention and training in this area across cultures, a core set of ten generic life skills are identified. These are basic to every culture and can be used for promotion of psychosocial health in children and adolescents.

These skills are arranged in five sets as follows,

\section{Decision Making and Problem Solving}

2. Empathy and Self-awareness

3. Communication Skills and Interpersonal Relationships

4. Coping with Stress and Coping with Emotions

5. Creative Thinking and Critical Thinking ${ }^{2}$

First and the most important aspect is that learning of life skills is essentially help to promote mental wellbeing. This enables one to deal effectively with every day challenges. Secondly, life skills education enables adolescents to learn and practice skills, as it is based on student centered and activity oriented methodology. Thirdly, life skills education is based on the philosophy that young people should be empowered to take more responsibility for their actions. Teaching ten generic skills is effective tool for promotion of mental wellbeing.

Millions of children live in the streets of cities scattered all over the world. Some estimates put the number of street children living in India's six most populous cities at $500,000^{1 .}$ In 2004 , out of the total juveniles, the share of homeless children who were involved in various crimes was just 7.5 percent. In Tamil Nadu there are over 1200 orphan and destitute children rescued and residing in the Government Homes. An in-depth study revealed that these children across Tamil Nadu lack the "collective efficacy" required for a socially-respectable life $\mathrm{e}^{3}$.

Research studies have shown various psychosocial factors and skills deficits that are the mediating to the development of various behavioral, psychological as well as health related problems. Low self-esteem, poor communication skills and problem solving skills, poor decision making skills and lack of assertiveness were found to be linked with delinquency ${ }^{4}$, school dropouts ${ }^{5}$, smoking, drug abuse ${ }^{6,7}$, teenage pregnancy, ${ }^{8,9}$, suicidal thoughts ${ }^{10}$ and health problems ${ }^{11}$. Considering these over the last decade there has been an increased interest in life skills among mental health professionals, Psychiatric Nurses, social workers and psychologists to provide today's children and adolescents with a set of skills for successful adaptation. This study was conducted to evaluate the effectiveness of Life Skills Training package (LSTP) on Life Skills, Self Esteem, Quality of Life and Academic Performance of children residing in selected orphanages

\section{Materials and Methods}

This study adopted a Quasi-experimental Pretest-posttest control group design. The present study was conducted at two selected orphanages in Tamil Nadu. Sri Kanyakumari Gurukulam girls Home, Alamelupuram, Karunkulam, Tirunelvelli District and Rehoboth Happy girls Home, Nagercoil, Kanyakumari District. Children with age twelve years to eighteen years old comprise the sample for the present study, totally 20 girls were selected randomly, 10 from each orphanages were assigned to experimental group, and control group. Data was collected using Social-demographic data sheet developed by the researcher, it dealt with details such as age, gender, religion, family type, parental status, educational status of father, educational status of mother, father's occupation, mother's occupation, family income, birth order, number of siblings, duration of stay in orphanage, background, educational status of child, academic performance, support system, study timings at the orphanage, child's attendance during the study hours, availability of teacher's during the study hours and made an extensive search of literature to find out different tools used for data collection in similar studies. Opinions were gathered from experts to identify the appropriate tools for the study. As a part of the assessment of life skills of children, the standardized tools used were Life Skills Scale, Vranda MN, (2007); Self-esteem of the children assessed using the Rosenberg Self-Esteem Scale, Rosenberg, M. (1965); Quality of life of the children by a standardized tool WHOQOL- BREF-26 and Academic record of the children issued by the School for assessing the Academic Performance. The tools were translated to Tamil language and checked for the reliability and utilization of tool $\mathrm{r}=0.839$. 
Data was collected in three phases. In first phase administrative permission from the Management and the In-charge of the orphanages was obtained. An informed consent was obtained from the children of the both groups for the willingness to participate in the study. Children were randomly allocated to the experimental and control group. Finally pretest was conducted with the tools on both groups. In second phase the life skill training Package (LSTP) was implemented for 4 hour per day for 5 days for the experimental group and in third phase post intervention data was collected after one week, one month, three month and six month after Life Skill Training Package (LSTP) by using same tools used in pre-test tools for children of both groups. Data were analyzed by using SPSS 17th version. Descriptive and inferential statistics were performed, the repeated measures ANOVA to compare the scores (of various tools) of each group over the various time points (preintervention to $4^{\text {th }}$ follow up). Additionally, for each of the tool at each time point, an independent sample $t$ test was performed to compare the average scores for the tools between the groups at that time point.

\section{Results and Discussions}

\section{Socio-demographic profile of children under study}

With respect to the age both in experimental group 50\% (5) and in control group 60\% (6) of the subjects belongs to age group 12-14 years. All subjects in experimental group belong to Hindu religion where as in control group $70 \%$ (7) of the subjects belongs to Hindu religion. In both the groups majority $40 \%$ (4) of the subjects have single parent. Family income in experimental group majority $40 \%(4)$ of the subjects were 1500 to $3000 \mathrm{Rs}$ and in control group $10 \%$ of subjects were above 5000 Rs. With respects to birth order, both the groups have $40 \%$ (4) of the subjects belongs to second order. In both the groups majority $40 \%$ (4) of the subjects have more than three siblings. In experimental group $40 \%$ (4) were staying 1- 2 years and $40 \%$ (4) were staying more than 5 years and in control group $50 \%$ (5) of the subjects were staying more than 5 years. Regarding the background, both the groups' subjects $70 \%$ (7) were from rural background. In experimental group $80 \%$ (8) and control group $70 \%$ (7), majority of the subjects were having primary support system. Both control and experimental group were homogenous in terms of age, gender, education, occupation, income, marital status, type of family, relation with the patient, number of people living with the patient, and bearer of treatment expenditure.
Table 2 reveals the Mean and Standard Deviation (SD) of the pre and post test scores of Experimental and Control groups on the life skills, self-esteem, quality of life and academic performance of the children residing in selected orphanages.

In the experimental group the Mean and SD of the pretest score in LSS $384.4 \pm 35.3$ indicates that children have low life skills whereas after the LSTP the post test score $441.2 \pm 52.1$ revealed higher life skills and in the control group the pretest score in LSS 314.9 \pm 35.1 and post test score was $315.6 \pm 30.1$ indicates lower life skills. Higher scores in the experimental group showed mastery over the life skills among children in orphanages

In the experimental group the Mean and SD of the pretest score in SES 16.9 \pm 3.4 where as in the post test score it was $20.1 \pm 3.4$ revealed higher scores, higher selfesteem and in the control group the pretest score was $13.9 \pm 2.9$ and the post test score was $14.8 \pm 2.7$

In the experimental group the Mean and SD of the pretest score in QOL was $94.7 \pm 12.9$ after the LSTP intervention higher score 100.6 \pm 13.9 denotes that higher quality of life and in the control group the pretest score was $77.7 \pm 7.3$ and the post test score was $74.8 \pm 6.2$.

In the experimental group the Mean and SD of the pretest score in Academic performance was $67.4 \pm 18.5$ (Grade-B) and the post test score it was 70.2 \pm 18.6 (Grade-B) which indicate there is some variation in the Academic achievement of children after LSTP and in the control group the pretest score was $57 \pm 10.3$ and the post test score was $55.8 \pm 8.5$ There was a gain in life skills, self-esteem, quality of life and improvement in the academic performance of the children residing in orphanage after the implementation of the Life Skill Training Package (LSTP) to the experimental group when comparing with the scores of control group.

Table-2 explains comparisons among pre, Immediate (PI), Post-II, Post-III and follow up assessments of the children in experimental group on the LSS, SES, QOL and Academic Performance. The repeated measures at five stages of the study were carried out to assess the life skills, self-esteem, quality of life and academic performance before, immediate, and during follow up after LSTP attended by the children in experimental group. Friedman repeated measures ANOVA for significant difference among the different levels of assessment. It is found on life skills there is significant 
difference $(\mathrm{p}<0.05)$ and self-esteem there is significant difference $(\mathrm{p}<0.001)$ among pre assessment, and four levels of post assessment of the children in experimental group. This implies statistically that, children in experimental group had higher life skills and self-esteem at post assessments than at pre assessment.

Table.1 Pre and posttest comparison between experimental group and control group on the scores of Life skills scale (LSS), Self-esteem scale (SES), Quality of life (QOL) and Academic performance of children residing in orphanages $(\mathrm{N}=20)$

\begin{tabular}{|c|c|c|c|c|c|}
\hline \multirow[t]{2}{*}{ Variables } & \multirow[t]{2}{*}{ Time } & \multicolumn{2}{|c|}{ Experimental Group $(\mathrm{n}=10)$} & \multicolumn{2}{|c|}{ Control Group $(n=10)$} \\
\hline & & Mean & SD & Mean & SD \\
\hline \multirow[t]{2}{*}{ LSS } & Pre test & 384.4 & 35.3 & 314.9 & 35.1 \\
\hline & Post test & 441.2 & 52.1 & 315.6 & 30.1 \\
\hline \multirow[t]{2}{*}{ SES } & Pre test & 16.9 & 3.4 & 13.8 & 2.9 \\
\hline & Post test & 20.1 & 3.4 & 14.8 & 2.7 \\
\hline \multirow[t]{2}{*}{ QOL } & Pre test & 94.7 & 12.9 & 77.7 & 7.3 \\
\hline & Post test & 100.6 & 13.7 & 74.8 & 6.2 \\
\hline \multirow[t]{2}{*}{ Academic Performance } & Pre test & 67.4 & 18.5 & 57.0 & 10.3 \\
\hline & Post test & 70.2 & 18.6 & 55.8 & 8.5 \\
\hline
\end{tabular}

Table.2 Within-group comparison among pre, post and follow up assessments of the children in experimental group on the scores of life skills scale (LSS), Self-esteem scale (SES), Quality of life (QOL) and

Academic performance of children residing in orphanages $(\mathrm{N}=20)$

\begin{tabular}{|c|c|c|c|c|c|c|c|c|c|c|c|}
\hline \multirow[t]{2}{*}{ Variables } & \multicolumn{2}{|c|}{ Pre $(n=10)$} & \multicolumn{2}{|c|}{ Post $1(n=10)$} & \multicolumn{2}{|c|}{ Post $2(n=10)$} & \multicolumn{2}{|c|}{ Post $3(n=10)$} & \multicolumn{2}{|c|}{ Post $4(n=10)$} & \multirow{2}{*}{$\begin{array}{l}\text { P- } \\
\text { value }\end{array}$} \\
\hline & Mean & SD & Mean & SD & Mean & SD & Mean & SD & Mean & SD & \\
\hline LSS & 384.40 & 35.31 & 441.2 & 52.1 & 436.0 & 59.8 & 464.8 & 60.51 & 436.1 & 44.71 & 0.04 \\
\hline SES & 16.9 & 3.4 & 20.1 & 3.4 & 23.4 & 3.7 & 22.9 & 3.2 & 17.6 & 2.6 & 0.00 \\
\hline QOL & 94.7 & 12.9 & 100.6 & 13.7 & 105.1 & 16.5 & 109.5 & 14.3 & 102.4 & 10.3 & 0.21 \\
\hline $\begin{array}{l}\text { Academic } \\
\text { Performance }\end{array}$ & 67.4 & 18.5 & 70.2 & 18.6 & 69.1 & 16.9 & 71.8 & 16.7 & 72.1 & 14.8 & 0.07 \\
\hline
\end{tabular}

\section{Group-wise comparison}

It is found that the total score of life skills, there is significant difference $(\mathrm{p}<0.001)$ at all the levels of assessments (pre, post-I, II, III, IV) of the children between experimental and control group. With respect to self-esteem except pretest scores $(p<0.05)$, and post assessments were found to be significant $(p<0.001)$. The total score of quality of life have significant difference $(\mathrm{p}<0.001)$ at all the levels of assessments (pre, post-I, II, III, IV) between experimental and control group. Academic performance found significantly different $(\mathrm{p}<0.05)$ in post assessments (post-I, III and IV). This implies that the children in experimental group gained higher life skills, increased selfesteem, higher quality of life and improvement in academic performance of children in orphanages than those in control group and in follow up comparison there was retention of life skills, self-esteem and quality of life, and improvement in academic performance among children in experimental group than in with control group.

Children living in orphanages face physical, psychosocial problems and stigmatized being poor, and being in orphanage. They are deprived of love and parental care.
Intervention for children is a big challenge for both government and nongovernmental organization. They need both short and long term interventions at individual level. In view of this Life Skill training package was administered to promote mental health and as a preventive measure. This study aimed to enhance the life skills, self-esteem, quality of life and academic performance of the children. This study shows that majority $50 \%$ in experimental group and in control group $60 \%$ of the children belong to age group 12-14 years. In both the groups' majority $40 \%$ of them have single parent. In both the groups' majority of children were in below poverty line. With respects to birth order, both the groups have $40 \%$ of the children belongs to second birth order. In experimental group d $40 \%$ were staying more than 5 years and in control group $50 \%$ of the subjects were staying more than 5 years in the orphanage. It was found that both the groups' subjects $70 \%$ were from rural background. In experimental group $80 \%$ and control group $70 \%$ of the children were having primary support system.

In this study the mean pretest score of life skills in the experimental group was 384.4 and the post test score was 441.2 and in the control group the pretest score was 314.9 and the post test score was 315.6. Similar findings were 
reported in the studies conducted Parvathy and Renjith $\mathrm{R}$ Pillai (2015) and Pujar et al., (2014). A study conducted by Vernosfaderani (2014) revealed that there was enhancement of self-esteem after implementation of Life skills training programme this study also found that in the experimental group the mean pretest score in Self-esteem was 16.9 and the post test score was 20.1 and in the control group the pretest score was 13.7 and the post test score was 14.8.

It was identified in the experimental group the Mean pretest score in quality of life as 94.7 whereas the post test score was 100.6 and in the control group the pretest score was 77.7 and the post test score was 74.8. Similarly in a study conducted by Tahereh et al., (2012) the findings revealed significant difference in the quality of life in psychological health, social relationship. In the experimental group the mean pretest score in Academic performance of the children were 67 and the post test score was 70 and in the control group the pretest score was 57 and the post test score was 55.8. Reza (2012) conducted a study the results showed that the students who had received academic and life skills training gained significantly higher scores in life skills and academic achievement than those with no training. There was significant gain in life skills, improved self-esteem, quality of life and improvement in the academic performance of the children residing in orphanage after the implementation of the Life Skill Training Package (LSTP) to the experimental group when comparing with the scores of control group. It also noted that there was retention in life skills, higher self-esteem and quality of life among experimental group children during follow up comparison.

In this present study the finding revealed a significant improvement in the Life skills, Self-esteem, Quality of life for the children in experimental group who attended the Life Skills Training Package.

\section{References}

1. Bye L, Jussim L. A proposed model for the acquisition of social knowledge and social competence. Psychology in the Schools. 1993; 30: $143-161$.

2. Cairns RB, Neckerman HJ, Cairns BD. Social networks and the shadows of synchrony. In G. R. Adams (Ed.), Biology of adolescent behavior and development, Thousand Oaks, CA: Sage. 1989; Pp. $275-305$.

3. Choquet M, Kovess V, Poutignat, N. Suicidal thoughts among adolescents: An intercultural approach. Adolescence. 1993; 28 (111): 649 - 659.

4. Duckes RL, Lorch BB. Concept of self-mediating factors and adolescent's deviance. Sociological Spectrum. 1989; 9(3): 301 - 319.

5. http://www.indiangos.com/issue/child/street/statistics /issue 1.htm

6. Keddie A. Psychosocial factors associated with teenage pregnancy in Jamaica. Adolescence. 1992; 27(108): 873 - 890.

7. Kumfer KL, Turner CW. The social ecological model of adolescent substance abuse: Implication for prevention. International Journal of the Addictions. 1990; 25(4): 495 - 463.

8. Parvathy V, Renjith R. Impact of Life Skills Education on Adolescents in Rural School, International Journal of Advanced Research, 2015; 3(2): 788-794.

9. Pickworth, G. 1989. Life skills training and career development from a career guidance perspective. Masters Dissertation, Pretoria, University of Pretoria.

10. Plotnick RD. The effects of attitudes on teenage premarital pregnancy and its resolution. American Sociological Review. 1992; 57(6): 800 - 811.

11. Pujar LL, Hunshal SC, Bailur KB. Impact of intervention on life skill development among adolescent girls, Karnataka J. Agric. Sci. 2014; 27 (1): 93-94

12. Reza F. Effectiveness of Academic and Life Skills Instruction on the Freshmen Academic Achievement, J. Life Sci. Biomed. 2012; 2(4): 137-141.

13. Singh H, Mustapha N. Some factors associated with substance abuse among secondary school students in Trinida and Tobago. Drug Education. 1994; 24(1): $89-93$.

14. Tahereh MH, Shahram M, Mohammad H. The Effectiveness of life skills training on happiness, quality of life and emotion regulation, Procedia Social and Behavioral Sciences. 2011; 30: 407 - 411

15. Vernosfaderani A. The Effectiveness of Life Skills Training on Enhancing the Self-Esteem of Hearing Impaired Students in Inclusive Schools, Open Journal of Medical Psychology, 2014; 3 (1).

16. WHO. 1993. Life Skills Education in schools (WHO/MNH/PSF/93.A Rev.1), WHO, Geneva.

\section{How to cite this article:}

Joseph Jeganathan and Reddemma, K. 2017. Preliminary Results from a Pilot Study on Effectiveness of Life Skills Training Package (LSTP) on Life Skills, Self Esteem, Quality of Life and Academic Performance among Children Residing in Selected Orphanages, Tamil Nadu. Int.J.Curr.Res.Aca.Rev. 5(7), 33-37.

doi: https://doi.org/10.20546/ijcrar.2017.507.006 